\title{
MICRO E PEQUENAS EMPRESAS (MPES) E COMPRAS PÚBLICAS NO CONTEXTO DO DESENVOLVIMENTO TERRITORIAL SUSTENTÁVEL: UMA ANÁLISE DO MUNICÍPIO DE GUARATUBA
}

\author{
Saulo Lúcio Mendes (UFPR) \\ Gestor Público - Universidade Federal do Paraná - Setor Litoral \\ Elaine Cristina de Oliveira Menezes (UFPR) \\ Professora do Curso de Administração Pública e do Programa de Pós- \\ graduação em Desenvolvimento Territorial Sustentável - Universidade Federal \\ do Paraná - Setor Litoral
}

\begin{abstract}
RESUMO: Objetivo central deste estudo é o de analisar se a Lei Complementar (LC) 123/2006 tem contribuído para a ampliação das MPEs no município de Guaratuba, buscando compreender como as MPEs estão sendo introduzidas em licitações e contratos públicos e se tal medida caminha rumo a dinâmicas de desenvolvimento mais sustentáveis do ponto de vista social, econômico e ambiental. Para tanto, mobilizou-se os conceitos do Desenvolvimento Territorial Sustentável, Empreendedorismo e Compras Públicas. Foi utilizada uma abordagem predominantemente quantitativa, com base nos dados obtidos da RAIS das MPEs de Guaratuba de 1997 a 2006 e de 2006 a 2015, bem como uma entrevista semiestruturada com o gestor público local. Os principais resultados da pesquisa reforçam que a LC 123/2006 não influenciou na ampliação do número de MPEs no município de Guaratuba. Houve aumento no número de estabelecimentos em 55,27\% nas microempresas, $90 \%$ nas pequenas empresas no período de 1997-2006 e 65,02\%microempresas e $56,14 \%$ pequenas no período de $2006-2015$, ou seja, com relação ao primeiro período, houve aumento de $9,75 \%$ somente no número das microempresas, com queda de $-33,86 \%$ nas pequenas empresas no segundo período. Porém, na geração de vínculos, no período de 2006-2015 as microempresas corresponderam num aumento de $347,01 \%$ dos vínculos e as pequenas empresas em $202,55 \%$. Os números demonstram que no primeiro período houve redução de $-26,23 \%$ das vagas ocupadas, tendo um aumento acentuado no segundo período de $270,44 \%$.
\end{abstract}

Palavras-chave: Desenvolvimento Territorial Sustentável; Empreendedorismo; Compras Públicas.

\section{INTRODUÇÃO}

O desenvolvimento territorial sustentável (DTS) é um conceito complexo que envolve diversificados elementos e atores. O ponto de partida para a 
abordagem do DTS é a crítica ao desenvolvimento econômico puro e simples. Para fins deste estudo DTS é a integração de duas abordagens do desenvolvimento que buscam apontar outros elementos, além do econômico, para se atingir dinâmicas mais equilibradas de desenvolvimento.

A primeira vertente teórica para o conceito do DTS é a do Ecodesenvolvimento que visa o desenvolvimento econômico e social compatibilizado e harmonizado com a gestão racional do ambiente e se dá na obrigatoriedade de cada ecorregião valorizar os seus recursos próprios e a cultura local, a fim de satisfazer as necessidades fundamentais da população em matéria de alimentação, habitação, saúde, educação, etc. (SACHS, 1986). Necessidades que devem ser entendidas de maneira realista e específicas para cada território, evitando-se o mimetismo conforme destacado por Sachs (1986).

A outra abordagem que trouxe contribuições ao conceito de DTS é a do Desenvolvimento Territorial, que busca valorizar não somente a eficácia das relações mercantis entre homens e suas riquezas, mas a valorização das questões culturais, econômicas e sociais locais. Assim, o conceito de desenvolvimento territorial traz na sua essência a noção de território, não um espaço geográfico dado, mas que compreende um conjunto de elementos naturais e sociais construído historicamente conforme destacado por Pecqueur (2004).

Diante do quadro teórico apresentado, destaca-se que as políticas de promoção do desenvolvimento, entendido como esse conceito mais amplo, são importantes mecanismos que podem auxiliar os governos locais na elaboração e consolidação de políticas e instrumentos de gestão mais ajustados as necessidades locais, como é o caso do Plano Plurianual (PPA) do município e os demais planos municipais. É com o auxílio do planejamento governamental que o gestor público poderá demonstrar a significativa preocupação e a eventual obrigatoriedade do poder Executivo em ações de desenvolvimento como, por exemplo: busca de melhoria das condições de vida das pessoas; promoção de estratégias de geração de trabalho e renda; fortalecimento da cultura local; educação e entre outros elementos sociais. 
Nas políticas de promoção ao desenvolvimento há uma vertente que analisa o incentivo às Micros e Pequenas Empresas (MPEs) por meio de inserção nas licitações e contratos públicos como forma de estimular a geração de emprego e renda local. Essa política, no Brasil, emerge por meio da Lei complementar 123/2006 nos termos dos artigos 146, 170 e 179 da Constituição Federal de 1988. Tal Lei assegura às MPEs tratamento diferenciado e favorecido nas compras públicas no âmbito dos Poderes da União, dos Estados e dos Municípios, acesso ao crédito e ao mercado, associativismo. Além de disporem da unificação e redução da carga tributária com o Simples Nacional.

O objetivo dessa política foi de fortalecer a participação das MPEs na economia, visto que em 1985 o IBGE destacou que a participação das MPEs era de 21\% do PIB brasileiro. Segundo SEBRAE (2014) em 2001 a participação no PIB era de $23,2 \%$ passando a $27 \%$ em 2011. Segundo dados obtidos do SEBRAE (2014), a representação das MPEs em âmbito Nacional era de nove milhões, cuja participação no Produto Interno Bruto (PIB) era correspondente a $27 \%, 52 \%$ da mão de obra formal e $40 \%$ da massa salarial brasileira, sendo as principais geradoras de riquezas no Brasil.

Nesse sentido, é relevante destacar que as MPEs têm tido importante papel na geração de trabalho e emprego e no desenvolvimento econômico e social brasileiro. Todavia, elas são mais vulneráveis às oscilações do mercado e, portanto, não conseguem sobreviver num cenário em que a competição é desigual, em que as empresas de médio e grande porte possuem mais capacidades (SACHS, 2008). Dessa forma, a Lei complementar 123/2006 apresenta-se como uma proposta para tornar as MPEs menos vulneráveis no âmbito das compras públicas, resgatando o princípio da isonomia.

Destaca-se que as compras públicas e os contratos administrativos entre a esfera pública e privada, devem ocorrer, via de regra, mediante licitação. $O$ ordenamento jurídico que rege essas relações é a Lei 8666/93 que dispõe sobre as normas gerais de licitação concernente a obras, serviços, publicidade, compras, alienações e locações no âmbito dos Poderes da União, dos Estados e Municípios (LEI 8.666/1993, 2016). Subordinam-se ao regime desta Lei, além dos órgãos da administração direta, os fundos especiais, as autarquias, as 
fundações públicas, as empresas públicas, as sociedades de economia mista e demais entidades controladas direta ou indiretamente pela União, Estados, Distrito Federal e Municípios, conforme disposição do Art. $1^{\circ} \mathrm{e}$ parágrafo único. Nas licitações devem ser garantidas a plena observância ao princípio constitucional de isonomia (iguais devem competir com iguais e os desiguais com os desiguais), de seleção da proposta mais vantajosa para a administração e da promoção do desenvolvimento nacional sustentável, conforme Art. $3^{\circ}$ (LEI 8666/1993, 2016).

Além disso, em paralelo, deve-se atentar para os princípios da legalidade, da impessoalidade, da moralidade, da igualdade, da publicidade, da probidade administrativa, da vinculação ao instrumento convocatório e do julgamento objetivo, conforme descrição no Art. $3^{\circ}$ dessa legislação (LEI 8.666/1993, 2016). A Lei 8666/93 além de reger as compras governamentais, também, vem servindo como mecanismo de fiscalização das relações laborais de trabalho, pois, na fase de habilitação jurídica para as licitações, as instituições têm que estar em dia com a regularidade fiscal e trabalhista. Caso contrário, a empresa torna-se inabilitada.

É no âmbito dos conceitos supracitados que se baseia a proposta deste estudo, cujo objetivo central é o de analisar se a LC 123/2006 tem contribuído para a ampliação das MPEs no município de Guaratuba, buscando compreender como as MPEs estão sendo introduzidas em licitações e contratos públicos e se tal medida caminha rumo a dinâmicas de desenvolvimento mais sustentáveis do ponto de vista social, econômica e ambiental. A hipótese que sustenta o objetivo central deste trabalho é o fato de que o incentivo dado pela LC 123/2006, em que as MPEs são beneficiadas nas licitações, poderá ter ampliado o número de estabelecimentos e promovido a geração de emprego e renda no município em questão. Compreende-se que a inserção da MPEs nas compras públicas não é fator determinante para um desenvolvimento mais sustentável do ponto de vista econômico, social e ambiental. Seria limitado compreender como tal. Entretanto, entende-se que para melhoria da qualidade territorial, aspecto relevante para o Desenvolvimento Territorial Sustentável, a geração de trabalho e renda locais é fator relevante. Assim, o sentido é avaliar a existência no município de MPEs 
que poderiam corresponder às demandas das licitações, sem precisar contratar com empresas de fora e ser potencial de promoção de um desenvolvimento endógeno.

Sendo assim, procurou-se identificar o número de estabelecimentos de MPEs nos grandes setores do IBGE, antes da edição da LC 123/2006; analisar o crescimento ou não de MPEs no município pesquisado após a edição da LC 123/2006; apontar os limites e potencialidades da LC 123/2006 na dinamização ao desenvolvimento mais sustentáveis, na percepção do gestor público municipal. A seção a seguir apresentará os principais aportes teóricos do estudo.

\section{O CONTEXTO DO DESENVOLVIMENTO TERRITORIAL SUSTENTÁVEL}

O termo desenvolvimento durante muito tempo foi entendido pela ótica da economia como sinônimo de crescimento econômico. Todavia, o desenvolvimento econômico está relacionado à melhora da qualidade de vida das pessoas, além do aumento continuo da produção de bens e serviços (MENEZES, 2011). Os três grandes paradigmas do desenvolvimento partem de vertentes teóricas da economia descritas no trabalho de Andion (2007), sendo eles: o paradigma desenvolvimentista, o paradigma heterodoxo e o paradigma neoliberal.

O primeiro foi pautado no modelo fordista. Seu apoio encontrava-se na ação centralizadora e polarizadora do Estado. O Estado era visto como promotor e garantidor dos direitos básicos, cuja ideia relaciona-se ao desenvolvimento pautado no crescimento continuo e cumulativo (ANDION apud MENEZES, 2011). O segundo fundamentado nos conceitos centrais da teoria Marxista, adaptada por outras linhas de pensamentos: neomarxistas, estruturalistas e dependendistas (ANDION apud MENEZES, 2011). Essas linhas analisaram a inter-relação do desenvolvimento e subdesenvolvimento, concluindo que o subdesenvolvimento é o resultado histórico das relações de dominação dos cenários internacional e nacional (ANDION apud MENEZES, 2011). Celso Furtado (2000), reforça essa ideia ao destacar que a industrialização não é sinal de desenvolvimento quando reflete apenas a elevação da produtividade, há a necessidade de preocupação com o contexto social. E o último resgata os 
clássicos da teoria econômica, relacionadas à autorregularão do mercado (ANDION apud MENEZES, 2011). Essas reflexões contribuíram expressivamente para o reenquadramento analítico do desenvolvimento.

Todavia, tais correntes não conseguiam internalizar os custos sociais das atividades econômicas (KAPP, 1979). Dessa forma, a partir dos anos de 1960 há um debate relacionado à crise socioambiental. Tal crise se circunscreve no âmbito da supremacia da ideia de desenvolvimento pautado no crescimento econômico e na forma como esse desenvolvimento deveria ser medido. Sachs (1986) destaca que o desenvolvimento não se resume em aumento do processo produtivo e lucros, nem mesmo a industrialização é sinônimo de desenvolvimento. Esse novo modelo de desenvolvimento tem como ponto de referência as discussões empreendidas no âmbito das conferências das nações unidas, que culminaram no conceito de ecodesenvolvimento que é aquele estilo de desenvolvimento que atende às necessidades básicas da geração atual sem comprometer o atendimento das gerações futuras (SACHS, 1986; SACHS, 1993).

Nele concebe-se que a dinâmica propulsora de vida do homem no meio está na racionalização dos recursos naturais, na busca da qualidade de vida, na adaptação dos condicionamentos da produção, na redefinição dos modelos de consumo, do produto, do impacto dos assentamentos humanos sobre 0 ambiente, ou seja, na harmonização do indivíduo ao meio natural, as tecnoestruturas criadas e o meio social (SACHS, 1986). De acordo com Sachs (1986) a prática do conceito do ecodesenvolvimento se dá na obrigatoriedade de cada ecorregião valorizar os seus recursos próprios e culturais, afim de satisfazer as necessidades fundamentais da população em matéria de alimentação, habitação, saúde e educação. Necessidades que devem ser entendidas de maneira realista e específicas para cada território, evitando-se o mimetismo. É importante pensar em desenvolvimento econômico e social compatibilizado e harmonizado com a gestão racional do ambiente. Um dos elementos cruciais e favorável ao ecodesenvolvimento está na aposta em um regime sócio-político: i) dependente da forma em que o Estado regula o mercado; ii) que se responsabiliza com os gastos sociais e planeja estrategicamente sua maneira de 
gerenciar as políticas ambientais; iii) que fomenta a pesquisa e a criatividade dos fazedores de políticas regionais a pensarem a adaptação e implementação do ecodesenvolvimento (SACHS, 1986).

Diante do quadro teórico que fundamenta as teorias de desenvolvimento no campo econômico e da discussão sobre a problemática socioambiental, é importante destacar abordagens alternativas que emergem, a partir da II Guerra Mundial, o conceito de desenvolvimento territorial. Essa vertente alternativa de desenvolvimento tem como ponto de partida a crise do modelo fordista de produção. Esse modelo, baseado em grandes empresas, passa a ser repensado a partir das experiências dos Distritos Industriais italianos e que demonstraram a importância das Micro e Pequenas empresas para o desenvolvimento local ${ }^{1}$.

Segundo Pecqueur (2004), o desenvolvimento territorial coloca-se em uma dinâmica valorizadora não somente pela eficácia das relações mercantis entre homens e suas riquezas, mas as culturais, econômicas e sociais. Assim, o conceito de desenvolvimento territorial tem sua emergência a partir da compreensão da noção de território. Apesar das múltiplas interpretações, a definição mais próxima é a ligada à noção do território, correspondendo ao espaço relacionado a um conjunto de elementos naturais e sociais. É nesse contexto, por meio da junção dos agentes e processos físicos e humanos que é constituído a ocupação do espaço para sua apropriação e controle. Conclui-se que, o território não é somente um componente físico, mas social e político.

A noção de desenvolvimento territorial, assim, compreende duas características importantes, a primeira resume-se em uma recusa ao fechamento espacial, já que a interação local e global deve ser enfatizada e perseguida pelos atores locais; a segunda é a recusa da supremacia econômica, colocando-se o bem-estar da sociedade no centro do desenvolvimento (WILSON apud

\footnotetext{
${ }^{1}$ Diante desse quadro três correntes foram sintetizadas por Menezes (2009) e que fazem parte dessa abordagem do desenvolvimento territorial: os Distritos industriais, o Ambiente inovador e os Cluster. Para Menezes apud Courlet e Soulage (2009) os Distritos industriais foram impulsionados por um alto grau de especialização e forte divisão do trabalho; acesso à mão de obra qualificada; existência de fornecedores locais de insumos e bens intermediários; sistemas de comercialização e de troca de informações entre agentes (MENEZES, 2009). Com expectativa de reversão e superação da crise pós-guerra, os processos endógenos de desenvolvimento desempenharam um terreno fértil para a proliferação das pequenas empresas.
} 
CAZELLA). O processo de desenvolvimento territorial depende da abertura de mercado de maneira seletiva e diferenciada e da descentralização econômica.

Para viabilizar o desenvolvimento territorial é necessário o envolvimento de atores e elementos, cuja composição embarca a participação da sociedade, Estado e planejamento. A participação da sociedade está associada à responsabilidade de debater acerca do desenvolvimento, de tal forma que a população possa escolher suas metas e alocar recursos necessários disponíveis. O Estado deve desempenhar o papel fundamental na promoção do desenvolvimento territorial, cujo objetivo principal é contrabalancear a lógica desestruturante do mercado e fornecer os meios humanos e técnicos ausentes no território. Por último é preciso construir uma estrutura autônoma de planejamento do desenvolvimento, devendo respeitar a pluralidade dos atores sociais que constituem a base social (GODARD e CERON apud CAZELLA).

Assim, por meio da convergência dessas duas abordagens do desenvolvimento alternativo, o desenvolvimento territorial e o ecodesenvolvimento, é que surge o que se denomina desenvolvimento territorial sustentável. Este é, conforme Vieira (2006) um enfoque de planejamento e gestão territorial. Essa proposta emerge do processo de tomada de consciência dos problemas socioambientais. Como parte da composição à redefinição do desenvolvimento, coloca-se o ecodesenvolvimento como um estilo de desenvolvimento, focado no tratamento da problemática socioambiental; na priorização das finalidades sociais; na prudência ecológica; na autoconfiança; na autodeterminação e no reenquadramento ao sistema produtivo (SACHS, 1986).

Portanto, para Menezes e Vieira (2011, p.14) visto sob a ótica da DTS, o desenvolvimento deve contemplar todas as necessidades de manutenção da vida humana, incluindo nesse contexto a manutenção do meio social, cultural, político, econômico e biofísico. Diante dessa nova proposta de desenvolvimento, a ideia seria reorientar as ações produtivas locais a partir do reconhecimento dos riscos socioambientais. Assim, na seção a seguir apresentam-se as principais concepções de empreendedorismo no contexto do desenvolvimento territorial sustentável. 


\section{EMPREENDEDORISMO E DESENVOLVIMENTO TERRITORIAL SUSTENTÁVEL}

O termo empreendedorismo advém do francês entrepreneur, que de acordo com o dicionário (MICHAELIS, 2016) significa qualidade ou característica de quem realiza empreendimento. Empreendedorismo é um campo de estudo em administração ramificado da ciência econômica que, de acordo com o raciocínio de Shumpeter (1982) envolve atores e elementos interligados em uma complexidade de variáveis que buscam obter no campo da economia, ou, no âmbito da produção, as vantagens necessárias advindas do negócio e a satisfação das necessidades humanas. Shumpeter (1982), foi o precursor deste campo, pois enfatizou o papel do empresário inovador nas dinâmicas de desenvolvimento econômico. É o empresário inovador que realiza as alocações técnicas para a satisfação de necessidades que ainda não estavam visíveis no mercado.

A produção para Schumpeter (1982) significa realizar novas combinações de forças e coisas. No contexto do empreendedorismo, o indivíduo, na figura do empreendedor é a peça central desse fenômeno, sendo, o mesmo, responsável pela visão dos negócios e ação. Por meio da sua atuação pode-se obter na dinâmica do mercado o lucro ou prejuízo resultantes do seu empreendimento. Em outras palavras, o empreendedor é responsável pelo andamento dos negócios e o principal mediador entre produtor e consumidor. $O$ empreendedorismo pode ser entendido como o "espírito do capitalismo" (SHUMPETER, 1982), pois em seu cerne existe a ideia de empreendedor inovador e indivíduo que aproveita oportunidade de negócios.

Segundo Shumpeter (1982), o empreendedor é o articulador no processo da inovação, usa recursos e criatividade para implementá-la, cujo o impacto nesse contexto é a geração de riquezas econômicas. Mas é necessário esclarecer a diferenciação entre investidor de capital e empreendedor, pois, existem empresários que não são empreendedores e empreendedores que não são empresários. Shumpeter (1982) fez tal distinção ao afirmar que o empreendedor não é aquele que disponibiliza apenas somas de dinheiro para 
uma determinada empreitada, mas, aquele que combina recursos, percebe e aproveita novas oportunidades.

Outros teóricos como Hisrich e Peters (2004) corroboram com as concepções shumpeterianas, ao considerarem que o empreendedor é aquele que cria algo novo a partir da dedicação de tempo e esforço, apesar de riscos pertinentes. Além de o empreendedor ser dotado de capacidade de decisão, ele possui capacidade de organização e aceita lucros ou eventuais prejuízos resultantes de seus atos. Apesar de o empreendedorismo estar presente desde o início da humanidade, é na ascensão do sistema capitalista que o termo ganha espaço nas dinâmicas de desenvolvimento, justificando a mobilização deste conceito para compreender o dinamismo das micro e pequenas empresas nesse início do século XXI.

Todavia, para fins deste trabalho a concepção de empreendedor vai além da concepção estritamente econômica, visto que se concebe diferentes formas de empreender dentro e fora do mercado. Nesse sentido, é preciso reconhecer que é no empreendimento que o empreendedor faz acontecer sua arte, materializada no âmbito comunitário, dando a ele um sentido substantivo à economia (POLANYI, 2012). É nesse contexto que se faz necessário relacionar os pequenos negócios com as teorias supracitadas do desenvolvimento territorial sustentável.

No Brasil o pequeno negócio tem papel fundamental na geração de trabalho e emprego e receberam a nomenclatura de micro e pequenas empresas (MPEs). Esses empreendimentos são partes de diversificadas culturas conforme o meio em que estão inseridas e é nelas que se inicia o empreendimento. As MPEs exercem impacto no PIB brasileiro e é nela que se emprega parte da população economicamente ativa (IBGE, 2016).

A partir dessa perspectiva destaca-se que o empreendedorismo no Brasil está fortemente amparado pelas pequenas organizações. Portanto, a relação entre empreendedor e empreendimento é indispensável para compreensão do empreendedorismo, sabendo que de um lado é voltado ao sujeito com capacidade de inovar e de canalizar recursos necessários para geração de riquezas e de outro lado é voltado ao objeto, cujo mesmo é o alvo da arte do 
empreendedor. Do empreendimento surge a possibilidade do desenvolvimento econômico territorializado, pois as MPEs, em geral atendem mercados locais e geram trabalho e renda no nível local. Esse será o foco da discussão na próxima seção.

\subsection{AS MICRO E PEQUENAS EMPRESAS NO QUADRO DO EMPREENDEDORISMO BRASILEIRO}

A cada ano o empreendedorismo vem crescendo acentuadamente em âmbito brasileiro, aumentando não somente em número de estabelecimentos, mas, em contribuição à participação no PIB e na geração de emprego e renda (SEBRAE, 2014).

Segundo o SEBRAE (2014), em 1985 o IBGE destacou que a participação das MPEs era de $21 \%$ no Produto Interno Bruto (PIB) brasileiro e o levantamento feito pela Fundação Getúlio Vargas mostra que, em 2001 a participação no PIB era de 23,2\% passando a 27\% em 2011. Em 2014, segundo dados obtidos do SEBRAE, a participação das MPEs no PIB correspondia a $27 \%$, sendo responsável por 52\% da mão de obra formal e 40\% da massa salarial brasileira, fazendo delas as principais geradoras de riquezas no Brasil. O quadro descrito reforça a necessidade de incentivar os pequenos negócios, objetivo almejado com a promulgação da LC 123/2006.

É preciso reconhecer que as MPEs antes de alcançarem o ponto que se encontram atualmente, passaram por um período em que o país enfrentava reduzidas taxas de crescimento econômico e forte elevação do desemprego. O período marcado por esses eventos foi o de 1980-2003, onde os pequenos negócios passam a ser alvo da elevação da participação de mão de obra na estrutura ocupacional brasileira, vagas advindas da transferência das médias e grandes empresas, dinâmica que resultou em um conjunto de movimento no período (SANTOS, 2012).

A alta taxa de desemprego, principalmente no ano de 1990, as novas relações entre empresas de distintos portes, as novas formas de contratação de trabalho, via o processo de terceirização, da contratação de cooperativas e de trabalho autônomo e a expansão do serviço terciário (SANTOS, 2006), fizeram 
com que houvesse um impulso à abertura pequenos negócios, por meio do processo de desverticalização, subcontratação, terceirização e franquias. Fatores que alavancaram tanto para expansão do número de vínculos empregatícios como os dos assalariados, com ou sem carteira assinada (SANTOS, 2012).

O período foi marcado por mudanças nas estruturas produtivas e sociais, por meio do êxodo rural, crescimento da população urbana, mudança no comportamento do consumo, redução do salário e a altíssima concentração de renda (SANTOS, 2012). Nesse processo ocorre a viabilização dos pequenos negócios no meio urbano e a expansão dos pequenos negócios na produção industrial (SANTOS, 2012). No período além de ter ocorrido mudanças estruturais na produção, também foi marcado pela heterogeneidade social, como descreve Santos,

\begin{abstract}
Em uma sociedade marcada por extrema desigualdade - de propriedade, renda e padrões socioculturais, em um período de relativa estagnação econômica e enorme desemprego, o processo de expansão do segmento de pequenos negócios também foi muito desigual, contribuindo para uma forte expansão de ocupações que pode ser caracterizada como pertencentes a um segmento de serviçais (SANTOS 2012, p.169).
\end{abstract}

Segundo Madi e Gonçalves (2012), no cenário econômico brasileiro, onde a situação é caracterizada pela concentração e pela centralização de capital é indiscutível a presença das MPEs para o desenvolvimento nacional no viés da geração de emprego e renda e na sustentabilidade social e ambiental local. Dentro dessa perspectiva a inserção das MPEs necessita de vantagens competitivas peculiares que potencializem suas possibilidades de crescimento e seu desempenho no mercado de trabalho contemporâneo. Além de pensar seus desafios num cenário marcado por mudanças das estruturas produtivas em âmbito mundial. Ademais, é fato que os pequenos empreendimentos têm potencial de degradação socioambiental menor que os grandes empreendimentos. Carece-se de estudos e pesquisas que demonstrem essa afirmativa. Todavia, é inegável que as MPEs têm sido aliadas do desenvolvimento econômico e social brasileiro. 
Tendo em vista a importância das MPEs no contexto social e econômico, Madi e Gonçalves (2012) relacionam fundamentos para o bom desempenho das MPEs no Brasil:

1) Necessidade de aperfeiçoar os mecanismos públicos de apoio às MPEs no processo de desenvolvimento brasileiro em função de sua importância social e econômica.

2) Necessidade de homogeneização de critérios para definição das MPEs com impactos decisivos na avaliação das condições de financiamento e na sustentabilidade das políticas públicas.

3) Necessidade de articulação das políticas de qualificação para a definição e o desenvolvimento de habilidades e competências dos trabalhadores.

4) Formulação de incentivos para a criação de Centros de Estudo da Produtividade que articulem os esforços de análises sobre oportunidades e limites para a permanência das MPEs. (MADI, GONÇALVES, 2012, P.36).

Outro aspecto relevante a ser considerado em estudos sobre MPEs são os critérios de classificação desses empreendimentos. No viés dos critérios de classificação que definem as MPEs, pode-se ter duas maneiras: i) número de pessoas ocupadas; ii) receita. Por números de pessoas ocupadas, entende-se que microempresas nas atividades de serviços e comércio comportam até 9 pessoas ocupadas e pequenas empresas de 10 a 49 pessoas ocupadas. No setor industrial, são microempresas aquelas com até 19 pessoas ocupadas, e pequenas empresas de 20 a 99 pessoas ocupadas, conforme quadro:

QUADRO 1: CLASSIFICAÇÃO EMPRESAS DE MICRO, PEQUENO, MÉDIO E GRANDE PORTE

\begin{tabular}{|l|l|l|l|}
\hline Porte & Atividades & Econômicas \\
\hline & Serviço e Comercio & Indústria & \\
\hline Microempresa & Até 9 pessoas ocupadas & Até 19 pessoas ocupadas \\
\hline Pequena Empresa & $\begin{array}{l}\text { De } 10 \text { a 49 pessoas } \\
\text { ocupadas }\end{array}$ & $\begin{array}{l}\text { De 20 a 99 pessoas } \\
\text { ocupadas }\end{array}$ \\
\hline Média Empresa & $\begin{array}{l}\text { De } 50 \text { a 99 pessoas } \\
\text { ocupadas }\end{array}$ & $\begin{array}{l}\text { De 100 a 499 pessoas } \\
\text { ocupadas }\end{array}$ \\
\hline Grande Empresa & Acima de 100 pessoas & Acima de 500 pessoas \\
\hline
\end{tabular}

Além dos dados apresentados no quadro 1, baseado no número de pessoas ocupadas, tem-se a classificação baseada na receita anual, segundo a 
LC 123/2006, em que as empresas podem ser classificadas em até $R \$$ $360.000,00$ como microempresas e até $R \$ 3.600 .000,00$ como pequenas empresas.

Por meio do levantamento teórico e de dados empíricos percebe-se que as MPEs têm exercido papel fundamental em âmbito brasileiro. No que se refere ao desenvolvimento socioeconômico do país, tem aumentado não somente em número de estabelecimentos, mas, em termos de participação no PIB, contribuindo para a geração de emprego e renda. Apesar do porte das mesmas comportarem de 9 a 99 pessoas, são essas as vagas que fazem das MPEs as empresas que mais ocupam mão-de-obra no país e impactam em termos de participação na economia (SEBRAE, 2014). A seção a seguir irá apresentar em linhas gerais elementos relacionados a compras públicas e suas potencialidades ao empreendedorismo.

\section{COMPRAS PÚBLICAS E AS POTENCIALIDADES PARA ALAVANCAR O EMPREENDEDORISMO NO NÍVEL LOCAL}

O uso do poder de compra do Estado é um importante instrumento que favorece o desenvolvimento (SQUEFF, 2014). O município tem em sua disponibilidade um instrumento capaz de gerar emprego e renda e viabilizar o desenvolvimento local. Nesse contexto pensar estrategicamente políticas públicas de desenvolvimento é buscar desenvolver formas de incentivos para capacitação tecnológica e competitividade industrial, estimular empresas locais a aperfeiçoar a qualidade de bens, serviços e obras, além do incentivo a formação de parcerias e arranjos produtivos locais (APL) com ganhos para a economia e o desenvolvimento municipal (FERNANDES, 2009).

Segundo Fernandes (2009), o poder de compra vai além da aquisição de bens e serviços para suprir a demanda da administração pública, o processo canaliza políticas estratégicas locais de desenvolvimento econômico sustentável, refletindo no enfrentamento da pobreza com diminuição das desigualdades sociais. Também enfatiza que as MPEs exercem papel fundamental nessa dinâmica, pois, o poder de compra pelo poder público 
municipal, incentiva o crescimento econômico regional, garante a estabilidade de demandas para o setor produtivo e favorece a sobrevivência das MPEs.

O poder de compra, sendo utilizado para contratar com MPEs locais acarretam o retorno dessas receitas ao município por meio da geração de emprego gerado localmente, bem como por meio dos impostos arrecadados localmente. Portanto, ampliam a receita do município, podendo ser usada para a melhoria dos serviços públicos, onde criam-se condições para o processo de desenvolvimento sustentável.

Segundo Fernandes (2009) outros países do mundo já vêm dando destaque as MPEs estimulando e incentivando-as. Dado o potencial de desenvolvimento nacional, uma das estratégias de ampliação das MPEs é por meio da sua participação nas compras públicas. Desde a segunda guerra mundial os EUA vêm dando a elas tratamento diferenciado nas compras governamentais. O Japão criou uma Agência da Pequena e Média empresa em plena reconstrução do país pós-guerra, com o objetivo de desenvolver a economia local e regional, impedir a concentração do poder econômico e incluir as MPEs nas compras governamentais. A União Europeia (UE) devido a dificuldades das MPEs em participar nas licitações públicas aprovou um pacote de diretrizes comunitárias que impunha aos Estados-membro a adoção de disposições nas compras públicas com intuito de incluir as MPEs. No Brasil há um embrião de usar o potencial benefício desse instrumento como estratégia para o desenvolvimento econômico local e o fortalecimento das MPEs, na economia nacional.

Para corroborar com essa perspectiva, SEBRAE (2010) destaca que devido importância das MPEs no desenvolvimento socioeconômico do país, desde 1970, as mesmas passam a ser reconhecida como responsáveis pela evolução econômica e pela geração de emprego e renda. Tal fato é percebido, pois, com o passar do tempo as MPEs vêm aumentando em números absolutos e até mesmo em cenários de crises geram novas vagas de empregos. No Brasil segundo dados obtidos do SEBRAE (2010), no período compreendido entre os anos de 2000-2008, houve um aumento no número de MPEs, que passou de 4,1 milhões para 5,7 milhões. Nesse mesmo período, o número de empregos com 
carteira assinada, gerado pelas MPE, passou de 8,6 milhões, em 2000, para 13,1 milhões, em 2008, com o objetivo de incentivar e promover as MPEs (PESSÔA, COSTA, MACCARI, 2016).

Por conta da sua relevância, os pequenos negócios passaram a ser alvo das políticas públicas governamentais. Políticas que devem ser entendidas através da promulgação do Estatuto da Microempresa e Empresa de Pequeno Porte, a Lei do Simples Federal e o Regime Especial Unificado de Arrecadação de Tributos e Contribuições devidos pelas Microempresas e Empresas de Pequeno Porte (Simples Nacional), instituída pela Lei Complementar 123/2006, sendo esse o contexto do seu surgimento (SEBRAE 2010). A LC 123/2006 foi um complemento a esse pacote de medida governamental que assegura às MPEs tratamento diferenciado e favorecido nas compras públicas no âmbito dos Poderes da União, dos Estados e dos Municípios, acesso ao crédito e ao mercado, associativismo, além de disporem da unificação e redução da carga tributária com a criação do Simples Nacional.

O campo das compras públicas vem sendo uma grande oportunidade para os detentores dos pequenos negócios alavancarem suas vendas, principalmente no nível municipal. Nessa dinamização que é composta pela participação do Estado e Mercado, surgem possibilidades de desenvolvimento econômico e social, pois, a relação entre público e privado viabiliza esse alcance, caminhando no sentido de um novo modelo de gestão pública (DENHART, 2012).

Porém, é nesse cenário que surge a necessidade da formulação de políticas públicas voltadas à promoção do empreendedorismo, cuja, o objetivo é o de incentivo à participação do empreendedor nas licitações e o estimulo ao aumento do número de empresas que correspondam com as demandas das compras públicas municipais, caso contrário a lei se torna impotente.

As compras públicas e os contratos administrativos, devem acontecer, via de regra, mediante licitação, sendo necessário em observância bilateral, o cumprimento do ordenamento jurídico regido pela Lei 8666/93. Para compreensão do conceito de licitação, Di Pietro (1997, p.47), traduz esse instrumento como 
[...] procedimento administrativo pelo qual um ente público, no exercício da função administrativa, abre a todos os interessados, que se sujeitem às condições fixadas no instrumento convocatório, a possibilidade de formularem propostas dentre as quais selecionará a mais conveniente para a celebração de contratos.

A Administração Pública deve analisar a proposta mais vantajosa para a compra de bens e serviços que além de satisfazer suas necessidades e visar o interesse público corresponda com seu plano orçamentário.

$\mathrm{O}$ artigo $3^{\circ}$ da Lei 8666/93 destaca que a licitação destina-se a garantir a observância do princípio constitucional da isonomia, a seleção da proposta mais vantajosa para a administração e a promoção do desenvolvimento nacional sustentável e será processada e julgada em estrita conformidade com os princípios básicos da legalidade, da impessoalidade, da moralidade, da igualdade, da publicidade, da probidade administrativa, da vinculação ao instrumento convocatório, do julgamento objetivo e dos que Ihes são correlatos.

Já para as empresas interessadas, segundo Art. 27, as mesmas devem estar habilitadas juridicamente, serem qualificadas tecnicamente $\mathrm{e}$ economicamente e estarem em regularidade fiscal e trabalhista.

Nas compras públicas existem as denominadas modalidades de licitação, definida pela Lei 8666/93 como: Concorrência, Tomada de Preço, Carta-Convite, Leilão e Concurso. Posteriormente foi criada através da Lei 10.520/2002 outra modalidade de licitação, denominada, Pregão Eletrônico, essa tem o intuito de facilitar o processo licitatório em função do avanço tecnológico e da Tecnologia da Informação-TI. Para escolha da modalidade, a licitação obedece alguns critérios, conforme Lei 8.666/1993 (2016):

a) PARA OBRAS E SERVIÇOS DE ENGENHARIA

QUADRO 2: MODALIDADES PARA OBRAS E SERVIÇOS DE ENGENHARIA

\begin{tabular}{|l|l|}
\hline Modalidade & Valor \\
\hline Convite & Até $150,000,00$ \\
\hline Tomada de Preço & Até $\mathrm{R} \$ 1.500,000,00$ \\
\hline Concorrência & Acima de $\mathrm{R} \$ 1.500,000,00$ \\
\hline
\end{tabular}

FONTE: LEI 8.666/1993 (2016) 
b) PARA COMPRAS E SERVIÇOS

QUADRO 3: MODALIDADES PARA COMPRAS E SERVIÇOS

\begin{tabular}{|l|l|}
\hline Modalidade & \multicolumn{1}{|c|}{ Valor } \\
\hline Convite & Até $\mathrm{R} \$ 80.000,00$ \\
\hline Tomada de Preço & Até $\mathrm{R} \$ 650.000,00$ \\
\hline Concorrência & Acima de $\mathrm{R} \$ 650.000,00$ \\
\hline
\end{tabular}

FONTE: LEI 8666/1993 (2016)

O Pregão Eletrônico é uma modalidade usada para aquisição de bens e serviços comuns, para qualquer que seja o valor estimado da contratação. Lembrando que a licitação pode ser dispensada caso a aquisição seja de valores menores, conforme dispõe os incisos I e II do Art. 24 da Lei 8666/93. A modalidade Leilão, é a modalidade para venda de bens móveis e imóveis da administração pública e de produtos legalmente apreendidos e penhorados, a quem oferece o maior lance, já a modalidade Concurso, é a escolha de trabalho técnico, cientifico ou artístico vencedor, cuja, a instituição é um prêmio ou até mesmo uma remuneração pertinente.

Analisando o conceito e modalidades de licitação que a lei dispõe, que o Estado através do planejamento estratégico das aquisições de bens e serviços, pode desempenhar função reguladora do mercado e promover o desenvolvimento social. Além de estimular a atividade econômica, tal estratégia do Estado, promove a geração de novas vagas de emprego e equidade social em nível territorial, viabilizando nesse contexto o desenvolvimento. Hommen e Tsipouri (2000) sustentam essa ideia ao dizer que as compras podem ser usadas para o aumento das demandas, estimulo à atividade econômica e o emprego, proteger as empresas domésticas da competição externa, aumentar a competitividade, minimizar a disparidade regional e criar empregos.

As potencialidades governamentais existem a partir do momento em que o governo planeja, buscando, tanto o alavanque do empreendedorismo através do estimulo à competitividade, quanto aos benefícios sociais e ambientais como resultado das relações com a esfera privada. Dessa forma, o empreendedorismo deve ser alvo dos holofotes do governo local, pois, é o principal gerador de 
receitas, emprego e renda, sem o qual, os benefícios advindos das relações serão drenados para outras localidades.

Outra forma de suportar o empreendedorismo local é o uso articulado das compras públicas para fomento da inovação. Para Edler e Georghiou (2007) se dá no sentido de que os mercados fragmentados, marcados por assimetria de informação, podem não estar conscientizando ou informando acerca dos seus produtos e inovações aos compradores, sejam eles privados ou públicos, e que nesse cenário a ação governamental seria ideal para articular preferências e demandas.

Outros teóricos como Timmermans e Zabala-Iturriagagoitia (2013) argumentam a possibilidade do potencial das compras públicas em fomentar 0 chamado "empreendedorismo baseado no conhecimento" (knowledgeintensiveentrepreneurship).

De acordo com os autores supracitados, o empreendedorismo local deve ser alvo das políticas públicas, através desse mecanismo, do estimulo à inovação das empresas locais para que as mesmas sobrevivam em meio às oscilações sem prejudicar a competitividade. O princípio da isonomia deve ser resgatado, pois, são as empresas de pequeno porte as mais vulneráveis a essas oscilações. No cenário de mercado, a competitividade deve acontecer em disputa homogênea, devendo as empresas de pequeno porte competir com as pequenas e as de grande porte com as grandes.

\section{ASPECTOS METODOLÓGICOS}

Quanto aos aspectos metodológicos adotados para elaboração desse artigo, foi utilizada uma abordagem predominantemente quantitativa, com base nos dados obtidos da RAIS e na revisão de literatura pertinente ao tema. Segundo Richardson (1999), a pesquisa quantitativa é caracterizada pelo emprego da quantificação, tanto nas modalidades de coleta de informações quanto no tratamento delas por meio de técnicas estatísticas. Todavia, complementou-se o estudo com alguns elementos da abordagem qualitativa, que visa explorar particularmente as técnicas de observação e entrevistas devido 
à propriedade com que esses instrumentos penetram na complexidade de um problema (RICHARDSON, 1999).

A pesquisa é do tipo descritiva, pois busca fazer uma avaliação inicial do impacto da Lei Complementar 123/2006 no quadro das MPEs de Guaratuba de 1997 a 2006 e de 2006 a 2015. Esse tipo de pesquisa busca fazer afirmações para descrever aspectos de uma população ou analisar a distribuição de determinada características e atributos (RICHARDSON, 1999).

As fontes de dados mobilizadas no estudo foram secundárias, além da revisão bibliográfica, o estudo foi pautado nos dados da RAIS nos períodos de 1997 a 2006 e de 2006 a 2015, cuja a intenção foi analisar o impacto da Lei Complementar 123/2006 sobre o aumento do número das micro e pequenas empresas e uma eventual geração de emprego e renda. Além dos dados da RAIS, a pesquisa contou com dados primários obtidos por meio de entrevista semiestruturada com um gestor público da área de compras do município de Guaratuba. Além dos dados da RAIS também se valeu de bibliografias e documentos sobre o tema.

Quanto à análise dos dados foi baseada na análise documental, bem como análise descritiva do conteúdo obtido junto à base de dados do Ministério do Trabalho e Emprego - RAIS nos períodos de 1997 a 2006 e 2006 a 2015 e com base nos conceitos-chave apresentados a seguir:

QUADRO 4: PRINCIPAIS COMCEITOS DA PESQUISA

\begin{tabular}{|l|l|l|}
\hline D & Características locais & Caracterização do município: IDH, PIB, etc. \\
\cline { 2 - 4 } T & Empreendedorismo & $\begin{array}{l}\text { Número de MPEs por setores } \\
\text { Emprego MPEs por setores }\end{array}$ \\
\cline { 2 - 4 } S & Compras públicas & $\begin{array}{l}\text { Caracterização do processo licitatório e contratação no } \\
\text { município pesquisado } \\
\text { Inserção das MPEs no processo de compras públicas locais } \\
\text { Preocupação com sustentabilidade socioambiental }\end{array}$ \\
\hline
\end{tabular}

FONTE: ELABORADO PELO AUTOR COM BASE NA REVISÃO DE LITERATURA

A análise dos dados buscou relacionar os dados da RAIS avaliados aos conceitos mobilizados no decorrer da revisão de literatura conforme quadro 4 com os achados de pesquisa conforme as categorias e elementos de coleta e análise de dados apresentados acima. Utilizou-se o Excel como mecanismo de 
tratamento dos dados e apresentação dos resultados, bem como a análise das falas do entrevistado.

\section{DISCUSSÃO E RESULTADOS DE PESQUISA}

\subsection{CARACTERIZAÇÕES DO MUNICÍPIO PESQUISADO}

O município de Guaratuba localiza-se a leste do Estado do Paraná, no litoral do Paraná. Os limítrofes do município abrangem os municípios de Matinhos, Paranaguá, Morretes, São José dos Pinhais e Tijucas do Sul. Além disso, o município faz divisa com o Estado de Santa Catarina, cujos municípios são Itapoá e Garuva (IPARDES, 2016), conforme ilustrado na figura 1.

\section{FIGURA 1: MAPA DE GUARATUBA}

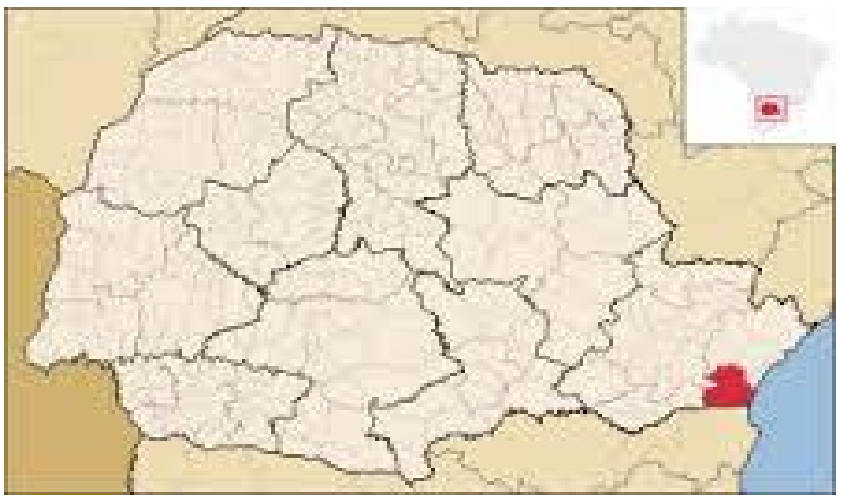

IPARDES (2016)

Guaratuba é um município localizado na região litorânea do Estado do Paraná. Sua área territorial é calculada em $1.328,480 \mathrm{~km}^{2}$ e a distância da Capital é de 117,73 km. O município é composto de dois distritos administrativos, Guaratuba e Pedra Branca do Araraquara, ambos pertencentes à Comarca de Guaratuba. Sua posição geográfica é composta de altitude em metros 15, latitude $25^{\circ} 52$ ' 58 " S, e longitude $48^{\circ} 34^{\prime} 29^{\prime}$ "W. A população estimada em 2016 é de 35.588 habitantes, o Índice de Desenvolvimento Humano Municipal (IDH-M) em 2010 correspondia em 0,717 (IPARDES, 2016) e o seu Produto Interno Bruto-PIB Per Capita correspondia, em 2013, em 14.749 (IPARDES, 2016).

As principais atividades econômicas (grandes setores do IBGE) do município são o comércio, os serviços e a agricultura. Sendo que em 2015 das 6.267 vagas ocupadas, o comércio era responsável por 2.109, os serviços 3.652 (IBGE, 2016). A agricultura, pecuária, produção florestal, pesca e aquicultura, 
empregavam em 2010, 1.586 pessoas (IPARDES, 2016). Segundo dados extraídos do Ipardes (2016) o número de estabelecimentos do setor de comércio e serviço, compreendem 915 das 1.069 do total de estabelecimentos, ou seja, 85,59\%. Em 2010 o município de Guaratuba ocupava a $144^{\circ}$ posição no ranking no estado e a $4^{\circ}$ em relação ao litoral em termos de IDH-M (IPARDES- 2016). A seção a seguir apresentará os principais resultados da pesquisa sobre MPEs no contexto das compras públicas.

\subsection{DESENVOLVIMENTO TERRITORIAL SUSTENTÁVEL E} EMPREENDEDORISMO: MPES NO CONTEXTO DAS COMPRAS PÚBLICAS EM GUARATUBA

A presente seção busca analisar os dados de número de estabelecimentos e emprego do município de Guaratuba antes e depois da promulgação da LC123/2006. Foram analisados dois períodos, o primeiro de 1997 a 2006 e o segundo de 2006 a 2015, onde averigua se houve aumento ou diminuição do número de estabelecimentos e empregos nas MPEs após promulgação da Lei Complementar referida acima.

A partir da pesquisa observou-se a evolução do número de estabelecimentos, por grandes setores do IBGE, dos períodos de 1997 a 2006 e de 2006 a 2015, conforme gráfico 1:

GRÁFICO 1: COMPORTAMENTO DO NÚMERO DE ESTABELECIMENTOS DE GUARATUBA DE 1997-2006 E DE 2006-2015

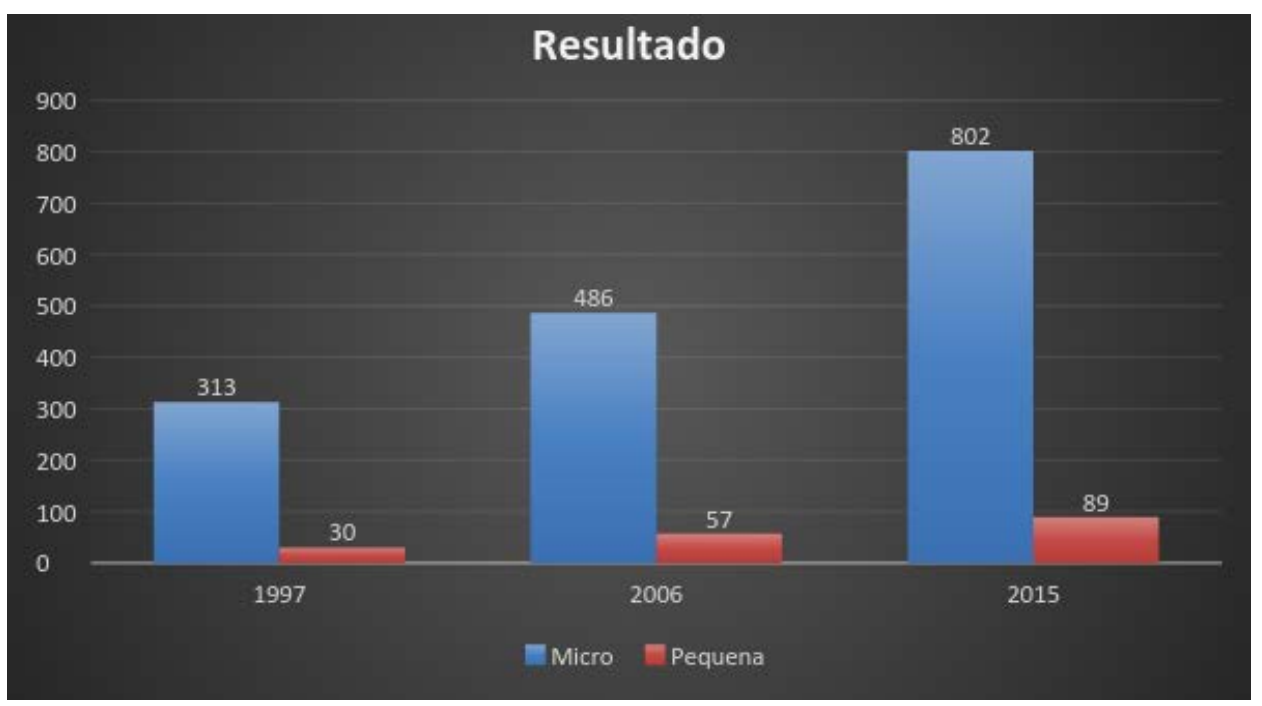

FONTE: RAIS (2016) 
De acordo com os dados referentes ao município de Guaratuba apresentado no gráfico 1, no ano de 1997 o número de microempresas era de 313 e de pequenas empresas de 30. Já em 2006 eram 486 micros e 57 de pequeno porte. Finalmente, em 2015 correspondiam a 802 microempresas e 89 de pequeno porte. Esses dados são referentes ao total de micro e pequenas empresas em seus respectivos anos extraídos dos principais setores da economia local, sendo eles: a indústria, construção civil, comércio, serviço e agropecuária. De 1997 a 2006 o aumento percentual das microempresas foi de $55,27 \%$ e das pequenas de 90\%, de 2006 a 2015 foi de 65,02\% e 56,14\%, respectivamente. Conforme observado as microempresas tiveram um crescimento $9,75 \%$ a mais que no primeiro período, já no viés das pequenas, no mesmo período cresceram $33,86 \%$ a mais.

TABELA 1: DADOS DO NÚMERO DE ESTABELECIMENTOS POR SETOR DO IBGE 1997-

2006 e 2006-2015

\begin{tabular}{|l|l|l|l|l|l|l|}
\hline & \multicolumn{3}{|c|}{1997} & \multicolumn{2}{c|}{2006} & \multicolumn{2}{c|}{2015} \\
\hline & MICRO & PEQUENA & MICRO & PEQUENA & MICRO & PEQUENA \\
\hline INDÚSTRIA & $\mathbf{2 4}$ & $\mathbf{1}$ & $\mathbf{3 7}$ & $\mathbf{3}$ & $\mathbf{5 8}$ & $\mathbf{2}$ \\
\hline CONSTRUÇÃO & $\mathbf{1 4}$ & $\mathbf{3}$ & $\mathbf{9}$ & $\mathbf{3}$ & $\mathbf{3 0}$ & $\mathbf{2}$ \\
\hline COMÉRCIO & $\mathbf{9 3}$ & $\mathbf{1 1}$ & $\mathbf{1 8 9}$ & $\mathbf{2 1}$ & $\mathbf{3 3 0}$ & $\mathbf{3 6}$ \\
\hline SERVIÇO & $\mathbf{1 7 5}$ & $\mathbf{1 5}$ & $\mathbf{2 4 1}$ & $\mathbf{2 9}$ & $\mathbf{3 5 0}$ & $\mathbf{4 8}$ \\
\hline AGROPECUÁRIA & $\mathbf{7}$ & $\mathbf{0}$ & $\mathbf{1 0}$ & $\mathbf{1}$ & $\mathbf{3 4}$ & $\mathbf{1}$ \\
\hline
\end{tabular}

FONTE: RAIS (2016)

Destaca-se, assim, que LC123/2006 não incentivou o aumento do número de MPEs no período de 2006-2015. O percentual de crescimento foi maior no primeiro período analisado de 1997-2006.

No levantamento do aumento do número de micro e pequenas empresas nos setores que mais crescem e empregam, o quadro descrito demonstra que o maior número de estabelecimento está nos setores comércio e serviço e que eventualmente são os principais responsáveis por exercerem grande participação no PIB e gerarem emprego e renda. Entretanto, percebe-se novamente a dúvida acerca da efetividade e eficiência da LC123/2006, pois, durante 1997 a 2006 o crescimento das MPEs no setor do comércio foi de $101,92 \%$, e no período de $1997-2015$ foi de $74,28 \%$, o primeiro período 
correspondeu em 27,64\% a mais que o segundo. No setor de serviços o primeiro período também demonstrou maior crescimento resultando em 5.39\%a mais.

QUADRO 5: NÚMERO DE VÍNCULOS GERADOS PELAS MPEs, PERÍODOS 1997-2006 e 2006-2015

1997

2006

2015

\begin{tabular}{|l|l|l|l|l|l|l|}
\hline & MICRO & PEQUENA & MICRO & PEQUENA & MICRO & PEQUENA \\
\hline INDÚSTRIA & $\mathbf{1 0 4}$ & $\mathbf{2 9}$ & $\mathbf{6 6}$ & $\mathbf{5 5}$ & $\mathbf{1 8 7}$ & $\mathbf{6 2}$ \\
\hline CONSTRUÇÃO & $\mathbf{5 0}$ & $\mathbf{6 5}$ & $\mathbf{1 2}$ & $\mathbf{1 1}$ & $\mathbf{9 0}$ & $\mathbf{5 0}$ \\
\hline COMÉRCIO & $\mathbf{2 4 5}$ & $\mathbf{1 8 9}$ & $\mathbf{1 8 7}$ & $\mathbf{1 0 5}$ & $\mathbf{9 6 1}$ & $\mathbf{6 3 0}$ \\
\hline SERVIÇO & $\mathbf{4 0 1}$ & $\mathbf{3 0 7}$ & $\mathbf{2 1 3}$ & $\mathbf{3 6 4}$ & $\mathbf{8 2 7}$ & $\mathbf{8 9 9}$ \\
\hline AGROPECUÁRIA & $\mathbf{9}$ & $\mathbf{0}$ & $\mathbf{7}$ & $\mathbf{1 2}$ & $\mathbf{1 0 3}$ & $\mathbf{1 4}$ \\
\hline
\end{tabular}

FONTE: RAIS (2016)

No levantamento dos dados foi seguida a mesma análise nos períodos de 1997 a 2006 e 2006 a 2015 para estabelecimentos. Assim, destaca-se os dados que podem demonstrar qual foi a influência dada pela LC 123/2006 no impacto da geração de emprego e renda.

Segundo dados obtidos da RAIS (2016), o total de vínculos gerados pelas MPEs até o ano de 1997, correspondia a 1399 empregos, em 2006 o número era de 1032. Já em 2015 esse número passou para 3823 empregos no total das MPEs. Os números demonstram que no primeiro período houve redução de $26,23 \%$ das vagas ocupadas, tendo um aumento acentuado no segundo período de $270,44 \%$. A redução do número de vínculos pelas microempresas no período de 1997-2006 foi de -40,04\% já das pequenas empresas foram de -7,28. É importante destacar que no primeiro período 1997-2006 somente as pequenas empresas do setor de serviços não tiveram redução, tendo um aumento de $18,56 \%$. No período de $2006-2015$ as microempresas corresponderam a um aumento de 347,01\% dos vínculos e as pequenas empresas em 202,55\%. Assim, o percentual de aumento foi maior no segundo período, como mostra tabela 2.

Os setores que mais geraram empregos foram os do comércio e serviço, mesmo com um período de redução das ocupações, foram responsáveis desde 2006 por um aumento de 29\% no setor de comércio no âmbito das microempresas e 235\%, no âmbito das pequenas. Entretanto destaca-se o setor 
de indústria que foi o terceiro que mais gerou empregos. No contexto social depreende-se que, a LC123/2006 conseguiu alavancar o número de vínculos, pois, é indiscutível o impacto da mesma no município de Guaratuba após sua promulgação.

\title{
6.3 COMPRAS PÚBLICAS E MPEs EM GUARATUBA: PERCEPÇÕES E CONSIDERAÇÕES
}

A pesquisa também contou com uma etapa qualitativa que buscou avaliar a percepção do gestor público municipal quanto a inserção das MPEs no contexto das compras públicas locais. Num primeiro momento, buscou-se avaliar como ocorre o processo de compras, para então compreender como a prefeitura tem inserido as MPEs no contexto das compras públicas e quais são as potencialidades e os limites para o município pesquisado.

Quando o representante da Prefeitura foi questionado sobre como ocorre o processo de compras públicas no município de Guaratuba o mesmo destacou que o processo se inicia com o pedido realizado pela Secretaria. Após há avaliação do pedido, para então o processo dar início conforme corroborado pela fala a seguir:

\begin{abstract}
"A secretária que demanda algum tipo de produto, serviço ou obra, solicita autorização da prefeita para licitação. Porém, é necessário justificar opor que da aquisição, sujeito a análise da prefeita, que julga de acordo com o interesse público. Com base nessa autorização o Departamento de compras dá início ao procedimento licitatório, com levantamentos de custos ou de cotação de preços quando se trata de produtos, a decisão é com base nos preços de custos e de referência, de acordo com esses valores e análises das condições técnicas é formatado um edital, ou, uma minuta de edital que posteriormente vai para apreciação do Departamento jurídico" (Representante da Prefeitura).
\end{abstract}

Quando indagado sobre quais as mudanças que vem ocorrendo na forma como a Prefeitura realizar compras públicas (licitação e contratação) no Município, o representante da prefeitura destacou que "a principal mudança foi o uso dos sistemas eletrônicos, antes eram feitos pregões presenciais e usávamos muito a modalidade convite, onde houve mudança para o pregão eletrônico. Iniciamos com o pregão eletrônico do Banco do Brasil, hoje utilizamos o da Caixa Econômica Federal" (Representante da Prefeitura). Dessa forma, 
constata-se que uso das Tecnologias de Informação e Comunicação são ferramentas aliadas no processo de gestão pública na percepção do gestor público municipal.

Quando questionado de quais secretarias têm demandado maior volume de compras públicas no município e quais os setores econômicos (indústria, comércio, serviços, agricultura) que mais são demandados para compras públicas em Guaratuba, destacou que, "as secretarias que mais demandam são Educação e Saúde e o setor econômico é o comércio". Tal constatação corrobora com o demonstrado nos dados da RAIS (2016) apresentados nas seções anteriores, cujos setores predominantes são comércio e serviço.

Ao buscar compreender se houve mudanças nos processos de compras públicas a partir da Lei Complementar 123/2006 que dá condições diferenciadas às MPEs, o Representante destacou que, sim, que houve uma mudança significativa em relação ao benefício e aos prazos para regularização documental. A partir dessa lei a prefeitura passou a fazer compras direcionadas exclusivamente as MPEs, segundo LC 147/2014, que trouxe alterações na LC 123/2006 conforme fala a seguir:

\footnotetext{
"Sim, nós mudamos significativamente, porque além da mudança com relação ao benefício e a questão de prazos para regularização de documentos, nós também através da LC 147/2014 passamos a fazer compra direcionada exclusivamente a MPEs, ou, com cotas reservadas" (Representante da Prefeitura).
}

No que se refere aos setores econômicos predominantes no município, se são suficientes para as demandas da Prefeitura de Guaratuba, ou, a maior parte das empresas que participam dos processos licitatórios é de outras regiões e de quais regiões, o Representante destaca que as empresas locais teriam competência para suprir as necessidades da prefeitura, mas na prática isso não tem ocorrido, pois as empresas contratadas geralmente são de Curitiba ou Joinville, corroborado pela fala a seguir:

\footnotetext{
"A rigor sim. Se analisarmos temos empresas com condições de fornecer para prefeitura, mas, na prática não é o que vem ocorrendo e que a maioria é de Curitiba, região metropolitana de Curitiba, Joinville, o que se percebe é que as MPEs locais têm dificuldade em relação a documentação" (Representante da Prefeitura).
} 
Quando questionado de como a prefeitura tem pensado a inserção das MPEs de Guaratuba e como tem contribuído para que essa Lei 123/2006 seja implementada, destacou que quanto a Lei já houve avanço. O representante da Prefeitura destacou que o que se tem estudado é a possibilidade de se fazer tratamento diferenciado no viés dos preços, pois, é necessário analisar o impacto disso no orçamento e no treinamento e formação das MPEs, como por exemplo, em propor parcerias com instituições de treinamento conforme corroborado pela fala a seguir:

\begin{abstract}
"Com relação à implementação da Lei já houve um grande avanço, o que se tem analisado hoje é a possibilidade de fazer tratamento diferenciado no que se refere a preços. Ainda não foi implementado, mas está em estudo porque precisa verificar o impacto disso nos custos e no aumento das despesas. Com relação às MPEs pensa-se em fazer parcerias com a associação comercial ou com entidades de treinamento, que viabilize uma preparação maior dos vendedores dessas empresas, pois, sentem muita dificuldade e desistem de participar antes mesmo de ler o edital" (Representante da Prefeitura).
\end{abstract}

Da mesma forma, quando questionado se as MPEs têm aparecido nos processos licitatórios de Guaratuba, o Representante respondeu que, "hoje a maior parte das contratações é com MPEs, menos obras maiores devido às mesmas não darem conta, pena que essas empresas não sejam do local" (Representante da Prefeitura).

Quanto aos benefícios de contratar com MPEs de Guaratuba para a Prefeitura e para o município, o representante da Prefeitura destacou que há vários fornecedores, de material de limpeza e material de construção com valores bem significativos. Porém, existem outros insumos importantes que a Prefeitura não tem de quem comprar, devido a regularidade fiscal das empresas, o baixo contingente para execução do procedimento, o preconceito e a dificuldade em esperar o pagamento devido ao volume adquirido nas compras, conforme destaca a fala a seguir:

\footnotetext{
"Sim, material de limpeza com valor bem significativo, material de construção, vários fornecedores locais, porem existem outros insumos importantes no processo que a prefeitura não tem de quem comprar no local, pois, as MPEs tem dificuldade em participar, além da irregularidade fiscal, falta de pessoal para execução do procedimento, preconceitos em relação ao processo, algumas tem dificuldade em esperar o pagamento por parte da prefeitura, que diferente de um
} 
consumidor normal, que paga no ato da compra, a prefeitura tem até 30 dias para pagar após a emissão da Nota Fiscal, e nem todas devido ao volume adquirido tem condição de suportar esse tipo de espera" ( Representante da Prefeitura).

Quando questionado sobre quais as dificuldades de inserir as MPEs nos processos licitatórios e nas contratações para as compras públicas municipais e quais são os principais problemas tanto da prefeitura, quanto das MPEs, o representante da Prefeitura destacou que, "Não há problemas com MPEs, elas têm fornecido a grande maioria de produtos e serviços e os eventuais problemas técnicos que ocorrem, aconteceriam em qualquer tipo de processo de compras sejam pequenas empresas ou grandes" (Representante da Prefeitura).

Contraditoriamente, quando o Representante foi indagado se a prefeitura tem pensado em diretrizes e tendências para a área de compras do município no sentido de fomentar a participação das MPEs nas licitações e nas contratações públicas municipais, esclareceu que, "A prefeitura já está comprando principalmente de MPEs, o que a prefeitura pensa é que as empresas locais sejam alvos das compras públicas, interessante para o município que esse recurso fique na localidade, e hoje a maior parte desse recurso vai para fora" (Representante da Prefeitura).

Dessa forma, destaca-se que há potencial de mercado para as compras públicas de Guaratuba principalmente no comércio e serviços, mas infelizmente as empresas locais ainda não conseguem absorver a ponto de a Prefeitura contratar com empresas da Grande Curitiba e de Joinville. Tais constatações podem advir de duas origens: uma que tem origem em uma lacuna em termos de comunicação entre a prefeitura e as empresas locais; outra seria relacionada a falta de capacitação profissional e técnica, bem como regularidade fiscal e trabalhista.

Com relação a como o processo de licitação e contratação de MPEs do município poderia contribuir para o desenvolvimento da região, o representante da Prefeitura destacou que se os recursos ficam no município, há a ampliação do número de empregos, o que alavanca os produtos e serviços da região e aquece a economia. Além disso, as MPEs tendem a gerar menos impacto socioambiental do que os grandes empreendimentos. Destacou o representante 
da Prefeitura que esse é o principal interesse municipal, que as pessoas estejam empregadas e que tenham qualidade de vida adequada, conforme fala a seguir:

\begin{abstract}
"Os recursos ficando no município aumentam a possibilidades de ampliar o número de empregos, alavanca outros produtos e serviços na região, porque quando o consumo e aqui acaba gerando mais empregos, e o empregado compra produtos e serviços daqui, gerando novos empregos, novos postos de trabalho, fazendo com que toda economia se aqueça. Fazer o que é de interesse do município, que as pessoas estejam empregadas e tenham um padrão de vida adequado é o intuito da prefeitura" (Representante da Prefeitura).
\end{abstract}

Quando questionado se os setores econômicos e empresas demandadas e contratadas nas compras públicas são setores preocupados com 0 desenvolvimento do município não somente do ponto de vista econômico, da geração de trabalho e renda, mas também preocupados com cuidado ao meio ambiente local, visto que há inúmeras regiões de preservação ambiental no Litoral. O representante da Prefeitura destacou que, sim, que é de conhecimento dos empresários locais que o município depende de um meio ambiente adequado e que o setor de compras junto aos técnicos da Prefeitura acompanha o tratamento e manipulação dos resíduos e há certa preocupação quanto a recepção dos produtos e serviços para que tudo ocorra adequadamente, conforme fala a seguir:

\footnotetext{
"Sim, o que se percebe é que grande parte dos empresários locais tem o conhecimento de que o município depende de um meio ambiente adequado. Nós do setor de compras temos exigido tratamento adequado em relação à resíduos, nas manipulações, e há uma preocupação em direcionar essas atividades. Os técnicos da Prefeitura quando recebem produtos ou serviços seguem essa observação de averiguar como está sendo a execução da obra e a entrega do produto, para que tudo ocorra adequadamente" (Representante da Prefeitura).
}

Diante do quadro apresentado até o momento, destaca-se que a Prefeitura tem se preocupado com maior inserção das MPEs nas compras públicas. Tem aprimorado seus mecanismos legais buscando se enquadrar nas alterações trazidas pela LC147/2014. Destaca-se para o fato de que o município ainda não contrata com MPEs somente de Guaratuba, demonstrando um potencial para as empresas locais. 
Todavia, demonstra que a tendência de ampliação das contratações públicas no nível local tem impactado positivamente, tanto no quadro da administração pública que amplia sua receita por meio do aumento da arrecadação de impostos, quanto no âmbito social, cujo impacto dá-se com o aumento do volume de empregos gerados localmente.

\section{CONSIDERAÇÕES FINAIS}

Entende-se que, a LC 123/2006 não influenciou na ampliação do número de MPEs no município de Guaratuba. O resultado mostra que houve aumento no número de estabelecimentos em 55,27\% nas microempresas, $90 \%$ nas pequenas empresas no período de 1997-2006 e 65,02\%microempresas e $56,14 \%$ pequenas no período de 2006-2015. O que se percebe é que no período de 2006-2015 as microempresas resultaram num aumento de $9,75 \%$ a mais que no período de 1997-2006, porem, no viés das pequenas empresas o aumento foi maior no primeiro período, correspondente a $33,86 \%$.

As MPEs têm recebido tratamento diferenciado nas licitações e contratos públicos no município de Guaratuba desde a promulgação da LC 123/2006. A Prefeitura mudou significativamente a sua forma de contratar, fazendo compras direcionadas exclusivamente as MPEs, buscando favorecer as empresas em relação ao preço, benefício e aos prazos para regularização documental.

Quanto ao ponto de vista socioambiental, é de conhecimento dos empresários locais que o município depende de um meio ambiente adequado, tendo o setor de compras junto aos técnicos da Prefeitura o compromisso quanto ao tratamento e manipulação dos resíduos, onde há certa preocupação com a recepção dos produtos e serviços para que tudo ocorra adequadamente. Além disso, há uma tendência de que os micro e pequenos empreendimentos impactem menos do ponto de vista socioambiental do que os grandes empreendimentos. Todavia, tais constatações, particularmente frentes a problemática socioambiental no município pesquisado pode ser adensada em pesquisas futuras. A abordagem de Sachs (1986) menciona que é importante pensar em desenvolvimento econômico e social compatibilizado com a gestão racional do ambiente. 
O incentivo dado pela LC123/2006 refletiu-se na geração de emprego e renda, conforme os dados da RAIS analisados nas seções anteriores. No período de 2006-2015 as microempresas corresponderam um aumento de $347,01 \%$ dos vínculos e as pequenas empresas em 202,55\%. Os números demonstram que no primeiro período houve redução de $-26,23 \%$ das vagas ocupadas, tendo um aumento acentuado no segundo período de $270,44 \%$. A redução do número de vínculos pelas microempresas no período de 1997-2006 foi de $-40,04 \%$ já das pequenas empresas foram de -7,28. É importante destacar que no primeiro período somente as pequenas empresas do setor de serviços não apresentaram redução, tendo um aumento de 18,56\%.

No município de Guaratuba o que têm ocorrido nas licitações é a pouca participação das MPEs da localidade, a maior parte dos contratos são com empresas da Grande Curitiba e de Joinville. O motivo é que as MPEs locais na maioria das vezes não correspondem com a demanda das licitações ou não podem participar devido às irregularidades fiscais, falta de pessoal qualificado para execução do procedimento. Além disso, algumas têm dificuldades em esperar o pagamento por parte da Prefeitura, que diferente de um consumidor normal, que paga no ato da compra, a Prefeitura tem até 30 dias para pagar, após a emissão da Nota Fiscal, mas nem todas, devido ao volume adquirido, têm condições de suportar esse tipo de espera. O que a Prefeitura tem como objetivo, pautado na LC123/2006, é fomentar a participação das MPEs locais no procedimento licitatório, pois, dessa forma os benefícios tanto econômicos quanto sociais ficam no local. Além disso, as universidades locais poderiam promover formação para os pequenos produtores, promovendo cursos de extensão com base na legislação de compras brasileira, para prepara-los à participação dos processos licitatórios nos municípios do litoral do Paraná.

Como limitações da pesquisa têm-se o fato desse estudo ter se aprofundado pouco nas questões socioambientais locais e no impacto das MPEs sobre o meio ambiente local, dando margens para pesquisas futuras. Como propostas de pesquisas futuras, também, sugerem-se que se façam análises no município com dados desagregados (CNAE 2005) para avaliar quais são os setores com potencial para as MPEs locais no âmbito das compras públicas, 
inclusivo apontando o potencial de mercado para futuros empreendedores locais.

\section{REFERÊNCIAS}

CAZELLA, Ademir, Antônio. As bases sociopolíticas do desenvolvimento territorial: uma análise a partir da experiência. UFSC. Florianópolis-SC- Brasil.

CRUZ, A.I.G, AMBROZIO, A.M.H, PUGA.F.P.H, SOUZA.F.L, NASCIMENTO.M.M. "A conquista brasileira: conquistas dos últimos dez anos, perspectivas para o futuro". BNDES. 2012.

DENHARDT, Robert B. Teorias da administração pública. São Paulo: Cenpage Learning, 2012.DI PIETRO, Maria Sylvia Zanella. Direito administrativo. 8a edição. São Paulo: Atlas 1997.

FERNANDES, J.V.J "O Município contratando com MPE" O estatuto da MPE fomentando a economia dos municípios. Jorge Ulisses Jacoby Fernandes. Brasília. SEBRAE, 2009.

FURTADO, Celso. "Formação econômica do Brasil”. 32 ed. São Paulo. 2005

HISRICH, R. D.; PETERS, M. P. Empreendedorismo. 5 ed. Porto Alegre: Bookman, 2004.

KAPP, Karl William. A natureza da economia como um sistema aberto e suas implicações. In: DOPFER, K. (org.). A economia do futuro - em busca de um novo paradigma. Zahar Editores: Rio de Janeiro, 1979, pp. 91-104.

IBGE. Censo 2010. Disponível em: < http://www.ibge.gov.br/home/ >. Acesso em: 21 set 2016.

LEI 8.666, de 21 de junho de 1993. Disponível em: < http://www.planalto.gov.br/ccivil_03/leis/L8666cons.htm >. Acesso em: 05 out 2016.

LEI COMPLEMENTAR123, de 14 e dezembro de 2006. Disponível em: < http://www.planalto.gov.br/ccivil_03/leis/LCP/Lcp123.htm >. Acesso em: 22 set 2016.

LORENÇO, Gilmar Mendes. "A macroeconomia Brasileira e Paranaense nos anos 2000". IPARDES. Curitiba, 2010.

MTE. Ministério do Trabalho e Emprego Disponível em <http://bi.mte.gov.br/bgcaged/> acesso em: 01 set 2016.

MENEZES, E. C. O. VIEIRA, P. H. F. Aglomeração industrial, governança e meio ambiente: conceitos e premissas da abordagem do desenvolvimento 
territorial sustentável. In: Revista Desenvolvimento e Meio Ambiente, v. X, n. 24, p. 101-118, jul./dez 2011.

MICHAELIS. Dicionário de Português. Disponível em: <http://michaelis.uol.com.br/>. Acessado em 20 de abril de 2016.

PESSÔA, Leonel Cesarino, COSTA, Giovane da MACCARI, Emerson Antônio. "As micro e pequenas empresas, o Simples Nacional e o problema dos créditos de ICMS" Revista direito GV, São Paulo. Mai-Ago 2016

POLANYI, Karl. A economia como processo instituído. In: LEVITT, Kari Polanyi (Org.). A subsistência do homem e ensaios correlatos. Rio de Janeiro: Contraponto, 2012. pp. 293-329.

RICHARDSON, R. J. Pesquisa social: métodos e técnicas. 3. ed. São Paulo: Atlas, 1999.

SACHS, Ignacy. Desenvolvimento: includente, sustentável, sustentado. Rio de Janeiro: Garamond, 2008.

SACHS, Ignacy. Ecodesenvolvimento: crescer sem destruir. São Paulo: Vértice, 1986.

SANTOS, A.L. Trabalhando em pequenos negócios no Brasil: Impactos da crise do final do século XX. 2006 (Doutorado). Instituto de economia/ Universidade Estadual de Campinas. Campinas; 2006a.

SANTOS, A.L. Trabalho informal dos pequenos negócios: evolução e mudanças no governo Lula. SANTOS, Anselmo Luís dos; KREIN, José Dari; CALIXTRE, André Bojikian (org). Micro e pequenas empresas: mercado de trabalho e implicação para o desenvolvimento. Rio de Janeiro: Ipea, 2012.

SCHUMPETER, Joseph A (1982). Teoria do desenvolvimento econômico: uma investigação sobre lucros, capital, crédito, juro e o ciclo econômico. São Paulo: abril Cultural.

SEBRAE. Anuário do trabalho na micro e pequena empresa 2009. 3. ed. São Paulo; Brasília, 2010

SEBRAE, Participação das Micro e Pequenas Empresas na Economia Brasileira. Brasília, 2014.

SQUEF, Flávia de Holanda Schmidt. O poder de compras governamental como instrumento de desenvolvimento tecnológico: análise do caso brasileiro.

Brasília: IPEA, 2014.

WASQUES, R.N, TRINTIN, J.G. A economia brasileira da década de 2000: ocorreu uma "Doença Holandesa" 